\section{JTI}

JOURNAL OF

TRAUMA AND INJURY

Received: March 5, 2019

Revised: June 2, 2019

Accepted: June 16, 2019

\section{Correspondence to}

Hee-Gon Park, M.D.

Department of Orthopaedic Surgery, Dankook University College of Medicine,

119 Dandae-ro, Dongnam-gu, Cheonan

31116 , Korea

Tel: +82-41-550-3954

Fax: +82-41-556-3238

E-mail: osdku@dankook.ac.kr

\title{
Essential Factors in Predicting the Need for Angio-Embolization in the Acute Treatment of Pelvic Fracture with Hemorrhage
}

\author{
Seok-Won Yang, M.D., Hee-Gon Park, M.D., Sung-Hyun Kim, M.D., \\ Sung-Hyun Yoon, M.D., Seung-Gwan Park, M.D. \\ Department of Orthopedic Surgery, Dankook University College of Medicine, Cheonan, \\ Korea
}

Purpose: The purpose of this study was to determine the essential factors for prompt arrangement of angio-embolization in patients with pelvic ring fractures.

Methods: A total of 62 patients with pelvic ring fractures who underwent angioembolization in Dankook University Hospital from March 2013 to June 2018 were retrospectively reviewed. There were 38 men and 24 women with a mean age of 59.8 years. The types of pelvic ring fractures were categorized according to the Tile classification. Patient variables included sex, initial hemoglobin concentration, initial systolic blood pressure, transfused packed red blood cells within 24 hours, Injury Severity Score (ISS), mortality rate, length of hospital stay, and time to angio-embolization.

Results: The most common pelvic fracture pattern was Tile type B ( $n=34,54.8 \%)$. The mean ISS was $27.3 \pm 10.9$ with $50 \%$ having an ISS $\geq 25$. The mean time to angio-embolization from arrival was $173.6 \pm 89$ minutes. Type B (180.1 \pm 72.3 minutes) and type $\mathrm{C}$ fractures (174.7 \pm 91.3 minutes) required more time to angio-embolization than type $\mathrm{A}$ fractures (156.6 \pm 123 minutes). True arterial bleeding was identified in types A (35.7\%), B (64.7\%), and C (71.4\%).

Conclusions: It is important to save time to reach the angio-embolization room in treating patients with pelvic bone fractures. Trauma surgeons need to consider prompt arrangement of angio-embolization when encountering Tile type B or C pelvic fractures due to the high risk of true arterial bleeding.

Keywords: Pelvis fracture; Angiography; Embolization; Management; Mortality 


\section{INTRODUCTION}

The management of pelvic fractures is significantly challenging for trauma surgeons in terms of life-threatening and functional outcomes. Even though advanced care, such as improvement of resuscitation algorithm, skeletal fixation, and critical care monitoring, has increased survival rate of these severely injured patients, the mortality rate is still significantly high [1]. Trauma patients with pelvic fractures are at risk of substantial hemorrhage, which can lead to a dreadful and fatal conditions. Mortality rates could increase up to $60 \%$ [2-4].

A wide variety of management methods, such as application of pelvic binder, external fixation, pelvic packing, and recently angio-embolization, have been suggested in treating patients with pelvic hemorrhage [5-7]. Basically, conventional measures and angio-embolization have been proposed as two different treatment modalities for pelvic hemorrhage control. Conventional measures, including pelvic packing and external fixation, mainly control venous and bone bleeding. In contrast, angio-embolization is mainly used to control arterial hemorrhage [8]. However, there are still ongoing debates on the best treatment strategy for patients with pelvic hemorrhage due to a combination of multisystemic injury patterns. This study evaluated the essential factors to consider in angio-embolization in treating patients with multiple traumas who were associated with pelvic ring fractures and retroperitoneal bleeding.

\section{METHODS}

\section{Patients}

After approval by the Institutional Review Board, we retrospectively reviewed 62 patients who were admitted to Dankook University Hospital and underwent angioembolization for pelvic fractures from March 2013 to June 2018. Patients who underwent emergent operation including external fixation or extra-peritoneal packing were excluded. The exact pelvic fracture patterns were categorized according to the Tile classification by two orthopedic physicians (S.Y.K and S.G.P.) based on computed tomography (CT) scan findings. Patient variables included age, sex, initial hemoglobin concentration, initial systolic blood pressure, transfused packed red blood cells (PRBCs) within 24 hours, Injury Severity Score (ISS), mortality rate, length of hospital stay, and time to angioembolization.

\section{Initial management and process of angio-embolization}

Standard Advanced Trauma Life Support protocols were administered by an organized trauma team $[9,10]$. Initial assessment included standard airway, breathing, circulation, and disability (neurological) survey, followed by careful physical examination to identify any injuries. Focused assessment with sonography for trauma (FAST) and plain radiography including the cervical spine, chest, and pelvis were performed in the trauma room upon arrival. When pelvic fractures were identified, a pelvic binder was applied for temporary mechanical stabilization. After evaluation of pelvic fracture pattern by CT scan, we removed binder on patients with lateral compression 1 and 2 type.

In accordance with the protocol of Dankook University Hospital, hemodynamic stabilization is the first step of treatment. If patients were hemodynamically unstable, crystalloid fluids were infused via central catheter, followed by PRBCs and fresh frozen plasma. When the patients were hemodynamically stable, they underwent contrastenhanced CT scan evaluation. In case of contrast extravasation and retroperitoneal hemorrhage, angio-embolization was sequentially performed. We try to super select vessel as many as possible under hemodynamically stable situation. However, if patients are hemodynamically unstable, entire internal iliac artery embolization could be done.

\section{Statistical analysis}

Statistical analysis was performed using SPSS version 21.0 (IBM Co., Armonk, NY, USA). ANOVA was used to derive the $p$-value for categorical variables. Values are reported as mean \pm standard deviation for continuous variables and percentage for categorical variables. $p<0.05$ were considered statistically significant. 


\section{RESULTS}

During the study period, a total of 62 patients with pelvic ring fractures were admitted and underwent angio-embolization. Seventeen patients were injured by traffic accidents, 24 by pedestrian accidents, 15 by falls, and 6 by crushing incidents (Table 1). The majority of the patients $(\mathrm{n}=34,54.8 \%)$ had a type B fracture, $22.5 \%(\mathrm{n}=14)$ had a type $\mathrm{A}$ fracture, and the remaining $22.5 \%(\mathrm{n}=14)$ had a type $\mathrm{C}$ fracture (Table 2 ). The mean age was $59.8 \pm 4.0$ years, and the mean ISS was $27.3 \pm 10.9$ with $50 \%$ having an ISS $\geq 25$. The mean time to angio-embolization from arrival was $173.6 \pm 89$ minutes. Even though, there was no significant difference in three groups. Types B (180.1 \pm 72.3 minutes) and $C$ fractures (174.7 \pm 91.3 minutes) require more time to angio-embolization than type A fractures (156.6 \pm 123 minutes). The overall mortality rate was $32 \%$ $(n=20)$, with type $C$ fractures having the highest mortality rate $(50.0 \%)$.

Table 1. The distribution of injury mechanisms, associated organ injuries, and combined fractures in other sites

\begin{tabular}{|lc|}
\hline Injury mechanism & Value \\
\hline Traffic accident & $17(27.4)$ \\
\hline Falling accident & $15(24.1)$ \\
Pedestrian accident & $24(38.7)$ \\
Crushing injury & $6(9.6)$ \\
\hline
\end{tabular}

Values are presented as number of patients (\%).
Table 3 describes the angiographically identified bleeding sources according to the Tile classification. While $35.7 \%$ of patients with type A fractures had true arterial bleeding, true arterial bleeding was more likely to develop in type B (64.7\%) and C (71.4\%) fractures. We could not find a correlation between pelvic fracture type and involved arterial bleeding source. However, the superior gluteal artery $(\mathrm{n}=14)$ and internal pudendal artery $(\mathrm{n}=13)$ were most frequently involved. No specific complications of embolization including necrosis or ischemia of tissues were observed.

\section{DISCUSSION}

Pelvic bone fractures tend to occur with high-energy forces, and patients with pelvic bone fractures are at risk of polytrauma, which leads to a high mortality rate [11-15]. Even though most vascular lesions in pelvic fractures often originate from veins or bone fracture site [16,17], they are more likely to have an arterial origin when patients are hemodynamically unstable [8]. In the study by Eastridge et al. [4], 58.7\% of patients who had both unstable pelvic fracture and persistent hypotension showed arterial bleeding. Likewise, Miller et al. [18] reported that $67.9 \%$ of patients had arterial bleeding as a cause of persistent hemodynamic instability. Based on these results, the importance of the time to angiography and embolization is supported by many reports when considering angio-embolization for

Table 2. Demographic and admission parameters, transfusion requirement and mortaliy stratified by pelvic fracture type

\begin{tabular}{|c|c|c|c|c|c|}
\hline & All patients & Type A ( $n=14)$ & Type B ( $n=34)$ & Type C ( $n=14)$ & $p$-value \\
\hline Age (years) & $59.8(4.0)$ & $64.8(4.7)$ & $60.2(3.0)$ & $54.2(4.7)$ & 0.32 \\
\hline Male (\%) & $61.2(38 / 62)$ & $42.8(6 / 14)$ & $67.6(23 / 34)$ & $64.2(9 / 14)$ & 0.277 \\
\hline Initial Hb (g/dL) & $9.9(2.6)$ & $9.6(2.1)$ & $10.0(2.8)$ & $9.8(2.8)$ & 0.896 \\
\hline Initial systolic BP (mmHg) & $102.2(29.8)$ & $113.5(33.9)$ & $99.1(27.7)$ & $98.3(29.9)$ & 0.273 \\
\hline Transfused PRBC within 24 hours (Pint) & $11.1(1.5)$ & $11.93(12.0)$ & $9.56(9.3)$ & $15.50(11.4)$ & 0.204 \\
\hline ISS score & $27.3(10.9)$ & $24.2(10.6)$ & $25.5(9.2)$ & $34.7(12.4)$ & 0.012 \\
\hline Mortality (\%) & 32 & 29 & 26 & 50 & 0.279 \\
\hline Length of hospital stay (days) & $38.5(45.2)$ & $50.2(51.7)$ & $37.1(48.6)$ & $30.3(26.1)$ & 0.498 \\
\hline Time to angio-embolization (minutes) & $173.6(89.0)$ & $156.6(123.0)$ & $180.1(72.3)$ & $174.7(91.3)$ & 0.696 \\
\hline
\end{tabular}

Values are presented as mean (standard deviation) or number unless otherwise indicated.

$\mathrm{Hb}$ : hemoglobin, BP: blood pressure, PRBC: packed red blood cells, ISS: Injury Severity Score. 
Table 3. According to fracture pattern, showing bleeding source and true arterial bleeding percentage

\begin{tabular}{|c|c|c|c|}
\hline Pelvic fracture type (Tile) & No bleeding focus & Bleeding source & Arterial bleeding \\
\hline$A(n=14)$ & 9 & $\begin{array}{l}\text { Superior gluteal }(n=2) \\
\text { Branch of internal iliac }(n=1) \\
\text { Inferior epigastric }(n=1) \\
\text { liolumbar }(n=1)\end{array}$ & $35.7 \%(5 / 14)$ \\
\hline$B(n=34)$ & 12 & $\begin{array}{l}\text { Superior gluteal }(n=9) \\
\text { lliolumbar }(n=1) \\
\text { Inferior gluteal }(n=3) \\
\text { Branch of interal iliac }(n=4) \\
\text { Obturator }(n=5) \\
\text { Internal pudendal }(n=12) \\
\text { lateral sacral }(n=1)\end{array}$ & $64.7 \%(22 / 34)$ \\
\hline$C(n=14)$ & 4 & $\begin{array}{l}\text { Superior gluteal }(n=2) \\
\text { Inferior gluteal }(n=2) \\
\text { Branch of internal iliac }(n=4) \\
\text { Internal pudendal }(n=1)\end{array}$ & $71.4 \%(10 / 14)$ \\
\hline$p$-value & & & 0.118 \\
\hline
\end{tabular}

the management of pelvic hemorrhage [19]. According to Agolini et al. [20], angio-embolization should be performed within 3 hours of patient admission to improve substantial survival rate. Hak et al. [21] demonstrated that survival rate improves when embolization is performed within 90 minutes of arrival. On the contrary, Evers et al. [22] showed the highest mortality rate after embolization (8 of 9 patients). The mean time was more than 4 hours from arrival to angiography. As a result, when managing a patient with pelvic hemorrhage, time to angiography is an essential factor to consider. Although nominated as a major trauma center, our hospital had a mean time of 173.6 minutes from admission to angiography, and mortality rate was $32 \%$. The delay in angio-embolization may be due to several reasons. Severe pelvic ring injuries are usually accompanied by polytrauma, such as brain hemorrhage and hemothorax [23]. The evaluation of multiple vital organs includes physical examination by the trauma team, FAST, CT scan, and radiography (cervical spine, chest, and pelvis), and this process requires some time. After evaluation and diagnosis are confirmed, acute resuscitation such as intubation, central line preparation, chest-tube insertion, or even resuscitative endovascular balloon occlusion of the aorta prolonged the time to angioembolization.
Based on the Tile classification, pelvic fractures can be divided into types A (stable), B (vertically stable, rotationally unstable), and C (vertically and rotationally unstable). Hauschild et al. [24] reported no significant statistical relation between the Tile classification and embolization. However, in the study of Barentsz et al. [25] 14 of 19 patients (74\%) who underwent embolization had Tile type C fractures, and three patients who died had Tile type $\mathrm{C}$ fractures. Wong et al. [26] concluded that severe pelvic hemorrhage with injury to the internal iliac artery is frequently found in patients with Tile type $\mathrm{C}$ fractures. Due to the proximity of the superior gluteal artery, fractures around the sciatic notch are more likely to result in arterial bleeding [19]. Widening of the symphysis pubis may indicate an increased risk of arterial injury [27]. However, multiple studies have shown no correlation between pelvic fractures and hemorrhage [28]. In the absence of pelvic fracture, arterial bleeding from the superior gluteal artery has been noted, and patients with seemingly low risk of pelvic fractures demonstrated exsanguinating hemorrhage. In our study, among 62 fractures classified according to the Tile classification, those with Tile types $\mathrm{B}$ (64.7\%) and C (71.4\%) were more likely to have arterial bleeding source. As reviewed in other studies, there was no significant correlation between fracture type and in- 
jured artery.

The decision to use angiography depends on several factors that include vital signs, continuous need for resuscitation, clinical scenario, and angiographer availability [29]. Although similar algorithms and guidelines are presented in many institutions, there is still no standard protocol for the use of angiography. Suspected pelvic arterial bleeding is the basic indication of angiography. When signs of shock are noted in patients, securing the airway and starting resuscitation should immediately be performed. Failure of resuscitative fluid use is an indication of possible hemorrhage investigation. Tanizaki et al. [30] considered hemodynamic instability on admission, which is defined as $<90 \mathrm{mmHg}$ systolic blood pressure after infusion of $2 \mathrm{~L}$ lactated Ringer's solution and initiation of PRBCs, as an indication of angiography. As mentioned previously, time to angiography is one of the most important factors of survival in pelvic hemorrhage. If a patient admitted to the ER has hemodynamic instability and Tile pelvic fracture types more than $\mathrm{B}$ or $\mathrm{C}$, trauma surgeons should always consider arranging angiography as soon as possible.

The limitations of our study are the small number of cases, its retrospective design, and no comparison between patients with pelvic fractures who underwent emergency surgery and conservative treatment. However, we conclude that our study contributes to establishing the importance of reducing the time to angiography and predicting factors before angiography.

\section{CONCLUSION}

Pelvic fractures associated with arterial bleeding can be effectively treated by angio-embolization. Even though, mortality rate and time to angio-embolization had no significant difference in our results. Our study gives message that more than 173.6 minutes to angio-embolization do not make any difference in survival rate even considering pelvis fracture type. Since many studies reported that time to angio-embolization from arrival affects mortality rate, emphasizing the importance to minimize the time to angio-embolization when treating a patient with true arterial pelvic hemorrhage cannot be overstated. Even though a statistically significant correlation between pelvic fracture type and existence of true arterial bleeding is not yet proven, surgeons should consider saving time for arrangement of angio-embolization in patients with pelvic fractures of Tile types more than $\mathrm{B}$ or $\mathrm{C}$ to improve the prognosis.

\section{REFERENCES}

1. Stein DM, O'Toole R, Scalea TM. Multidisciplinary approach for patients with pelvic fractures and hemodynamic instability. Scand J Surg 2007;96:272-80.

2. Cothren CC, Osborn PM, Moore EE, Morgan SJ, Johnson JL, Smith WR. Preperitonal pelvic packing for hemodynamically unstable pelvic fractures: a paradigm shift. J Trauma 2007;62:834-9; discussion 839-842.

3. Osborn PM, Smith WR, Moore EE, Cothren CC, Morgan SJ, Williams AE, et al. Direct retroperitoneal pelvic packing versus pelvic angiography: a comparison of two management protocols for haemodynamically unstable pelvic fractures. Injury 2009;40:54-60.

4. Eastridge BJ, Starr A, Minei JP, O'Keefe GE, Scalea TM. The importance of fracture pattern in guiding therapeutic decision-making in patients with hemorrhagic shock and pelvic ring disruptions. J Trauma 2002;53:446-50; discussion 450-1.

5. Costantini TW, Bosarge PL, Fortlage D, Bansal V, Coimbra R. Arterial embolization for pelvic fractures after blunt trauma: are we all talk? Am J Surg 2010;200:757-8.

6. Jeroukhimov I, Ashkenazi I, Kessel B, Gaziants V, Peer A, Altshuler A, et al. Selection of patients with severe pelvic fracture for early angiography remains controversial. Scand J Trauma Resusc Emerg Med 2009;17:62.

7. Magnussen RA, Tressler MA, Obremskey WT, Kregor PJ. Predicting blood loss in isolated pelvic and acetabular high-energy trauma. J Orthop Trauma 2007;21:603-7.

8. Lustenberger T, Wutzler S, Störmann P, Laurer H, Marzi I. The role of angio-embolization in the acute treatment concept of severe pelvic ring injuries. Injury 2015;46:S33-8.

9. Smith RF, Frateschi L, Sloan EP, Campbell L, Krieg R, Edwards $\mathrm{LC}$, et al. The impact of volume on outcome in seriously injured trauma patients: two years' experience of the Chicago Trauma System. J Trauma 1990;30:1066-75; discussion 1075-6.

10. Konvolinka CW, Copes WS, Sacco WJ. Institution and persurgeon volume versus survival outcome in Pennsylvania's trauma centers. Am J Surg 1995;170:333-40. 
11. Maqungo S, Kimani M, Chhiba D, McCollum G, Roche S. The L5 transverse process fracture revisited. Does its presence predict the pelvis fracture instability? Injury 2015;46:1629-30.

12. Ruatti S, Guillot S, Brun J, Thony F, Bouzat P, Payen JF, et al. Which pelvic ring fractures are potentially lethal? Injury 2015;46:1059-63.

13. Huang S, Vohora A, Russ MK, Mathew JK, Johnny CS, Stevens $\mathrm{J}$, et al. Delaying urinary catheter insertion in the reception and resuscitation of blunt multitrauma and using a full bladder to tamponade pelvic bleeding. Injury 2015;46:1081-3.

14. Balbachevsky D, Belloti JC, Doca DG, Jannarelli B, Junior JA, Fernandes HJ. Treatment of pelvic fractures - a national survey. Injury 2014;45 Suppl 5:S46-51.

15. Burkhardt M, Kristen A, Culemann U, Koehler D, Histing T, Holstein $\mathrm{JH}$, et al. Pelvic fracture in multiple trauma: are we still up-to-date with massive fluid resuscitation? Injury 2014;45 Suppl 3:S70-5.

16. Durkin A, Sagi HC, Durham R, Flint L. Contemporary management of pelvic fractures. Am J Surg 2006;192:211-23.

17. El-Haj M, Bloom A, Mosheiff R, Liebergall M, Weil YA. Outcome of angiographic embolisation for unstable pelvic ring injuries: factors predicting success. Injury 2013;44:1750-5.

18. Miller PR, Moore PS, Mansell E, Meredith JW, Chang MC. External fixation or arteriogram in bleeding pelvic fracture: initial therapy guided by markers of arterial hemorrhage. J Trauma 2003;54:437-43.

19. Vaidya R, Waldron J, Scott A, Nasr K. Angiography and embolization in the management of bleeding pelvic fractures. J Am Acad Orthop Surg 2018;26:e68-76.

20. Agolini SF, Shah K, Jaffe J, Newcomb J, Rhodes M, Reed JF 3rd. Arterial embolization is a rapid and effective technique for controlling pelvic fracture hemorrhage. J Trauma 1997;43:395-9.

21. Hak DJ, Smith WR, Suzuki T. Management of hemorrhage in life-threatening pelvic fracture. J Am Acad Orthop Surg 2009;17:447-57.

22. Evers BM, Cryer HM, Miller FB. Pelvic fracture hemorrhage. Priorities in management. Arch Surg 1989;124:422-4.

23. Ertel W, Eid K, Keel M, Trentz O. Therapeutical strategies and outcome of polytraumatized patients with pelvic injuries a six-year experience. Eur J Trauma 2000;26:278-86.

24. Hauschild O, Aghayev E, von Heyden J, Strohm PC, Culemann U, Pohlemann T, et al. Angioembolization for pelvic hemorrhage control: results from the German pelvic injury register. J Trauma Acute Care Surg 2012;73:679-84.

25. Barentsz MW, Vonken EP, van Herwaarden JA, Leenen LP, Mali WP, van den Bosch MA. Clinical outcome of intra-arterial embolization for treatment of patients with pelvic trauma. Radiol Res Pract 2011;2011:935484.

26. Wong YC, Wang LJ, Ng CJ, Tseng IC, See LC. Mortality after successful transcatheter arterial embolization in patients with unstable pelvic fractures: rate of blood transfusion as a predictive factor. J Trauma 2000;49:71-5.

27. Gourlay D, Hoffer E, Routt M, Bulger E. Pelvic angiography for recurrent traumatic pelvic arterial hemorrhage. J Trauma 2005;59:1168-73.

28. Cook RE, Keating JF, Gillespie I. The role of angiography in the management of haemorrhage from major fractures of the pelvis. J Bone Joint Surg Br 2002;84:178-82.

29. Langford JR, Burgess AR, Liporace FA, Haidukewych GJ. Pelvic fractures: part 1. evaluation, classification, and resuscitation. J Am Acad Orthop Surg 2013;21:448-57.

30. Tanizaki S, Maeda S, Matano H, Sera M, Nagai H, Ishida H. Time to pelvic embolization for hemodynamically unstable pelvic fractures may affect the survival for delays up to $60 \mathrm{~min}$. Injury 2014;45:738-41. 